Bull. Chem. Soc. Ethiop. 2017, 31(1), 51-62.

ISSN 1011-3924

(C) 2017 Chemical Society of Ethiopia and The Authors

Printed in Ethiopia

DOI: http://dx.doi.org/10.4314/bcse.v31i1.5

\title{
ADSORPTION OF ACID DYE ONTO ACTIVATED ALGERIAN CLAY
}

\author{
Djelloul Bendaho*, Tabet Ainad Driss and Djillali Bassou \\ Laboratory of Organic Chemical-Physical and Macromolecular Faculty of Exact Sciences, \\ University Djilali Liabès, Faubourg Larbi Ben m’hjdi P. O. Box. 89, Sidi Bel-Abbès 22000, \\ Algeria
}

(Received December 18, 2014; revised September 1, 2016)

\begin{abstract}
In this work, activated clay from Algeria was used as adsorbent for the removal of methyl orange (MO) from aqueous solution, for this, the effects of several parameters such as contact time, adsorbent dose, $\mathrm{pH}$ value of aqueous solution and temperature on the adsorption of MO were also studied. The results showed that nearly $30 \mathrm{~min}$ of contact time are found to be sufficient for the adsorption to reach equilibrium and the adsorption was favourable at lower $\mathrm{pH}$. The acid dye concentration is measured with UV-visible spectrophotometer at a wavelength of $464 \mathrm{~nm}$. The adsorption capacity of MO found to be $32.57 \mathrm{mg} / \mathrm{g}$. The Pseudo-first-order and pseudo-second-order models were used to fit the experimental data. The adsorption kinetic process was found to follow a pseudo second order model.The Langmuir and Freundlich isotherms models were used to describe adsorption data, the results indicates that Langmuir and Freundlich models provide better correlation of the experimental data. The negative values of $\Delta \mathrm{G}^{\circ}$ at different temperatures show that the adsorption process is spontaneous. The values of $\Delta \mathrm{H}$ and $\Delta \mathrm{S}$ were found to be $1.04 \mathrm{~kJ} / \mathrm{mol}$ and $3.35 \mathrm{~J} / \mathrm{mol} . \mathrm{K}$, respectively. The positive value of $\Delta \mathrm{H}$ confirms that the adsorption is endothermic and the adsorption process is chemical nature.
\end{abstract}

KEY WORDS: Dye, Adsorption, Cay, Adsorption kinetics, Adsorption isotherms

\section{INTRODUCTION}

Accumulation of dyes in wastewater from different industries such as dye synthesis, textiles, paper, cosmetics, printing, and plastics are one of the major sources of water pollution. These dyes are usually used in excess to make the dye better, and consequently sewage is highly concentrated with colorants. These dyes in surface waters are of barrier effect on the sun light penetration and aeration of water body, and thus reduce photosynthetic activity. Their removal from effluent by the use of conventional physico-chemical and biological processes is difficult [1] such as coagulation, ultra-filtration, electro-chemical adsorption and photo-oxidation, never the less these methods are not satisfying because of the weak colorant biodegradability [2-4]. The activated carbon is the effective alternate for the concentration of dye ions even in the case of lower solute concentration. However activated carbon adsorption is limited due to the high cost of activated carbon and the cost involved in regenerating it. In this way the majority of the processes are very selective according to the colorant categories to treat and some just move the pollution instead of removing it [5]. It is necessary for the process to mineralize the colorant. Adsorption technology has attracted interest in this context as an effective and alternative treatment process and has many advantages over the existing conventional process. This process is not only economic and feasible but also produces high quality of water [6]. The different applications of the activated-clay depend on their specific adsorption properties, the ion exchange and the surface nature [7]. Due to these qualities, clay is used in different field, like in medical and pharmaceutical industries, organic molecule polymerization [8] and pollutant retention such as pesticides, organic, inorganic compounds, heavy metals [9-10-11]. The removal of methyl orange from wastewater needs great attention. The aim of this paper is to

*Corresponding author. E-mail: bendaho_djelloul@yahoo.fr 
study the feasibility of using activated-clay as an adsorbent for the removal of an anionic dye, methyl orange and to determine the various parameters affecting sorption such as contact time, adsorbent dose, $\mathrm{pH}$ and temperature were evaluated and the adsorbent was characterized by DRX and FTIR. Kinetic and isotherm adsorption models are performed in order to better understand the organic colorant adsorption mechanisms [12].

\section{EXPERIMENTAL}

\section{Reagents and materials}

The adsorbate (methyl orange $\mathrm{MO}$ ). The dye used in this study is methyl orange, was purchased from Sigma-Aldrich. Having the chimical formula $\mathrm{C}_{14} \mathrm{H}_{14} \mathrm{~N}_{3} \mathrm{NaO}_{3} \mathrm{~S}$ and molecular weight of $327.33 \mathrm{~g} / \mathrm{mol}$, and $\lambda_{\max }: 464 \mathrm{~nm}$. The structure of this dye is shown in Figure 1.

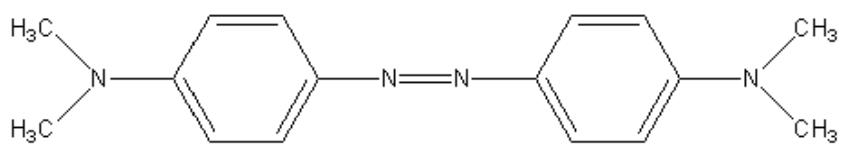

Figure 1. Molecular structure of methyl orange dye.

The adsorbent. We used a raw clay collected from the region of "Tiout", located in south Algeria. this last was dispersed in distilled water and maintained under constant stirring for 2 hours in order to remove impurities. The suspension was then filtered and dried at $105{ }^{\circ} \mathrm{C}$ to constant dry weight, then stored in a securely closed flask for use in the experiments.

Acid-activated clay. A mass of $20 \mathrm{~g}$ of raw clay was treated under mechanical stirring with 200 $\mathrm{mL}$ of sulfuric acid $(0.25 \mathrm{M})$ at room temperature for $24 \mathrm{~h}$. The resulting acidic activated clay was filtered, washed several times with distilled water until $\mathrm{SO}_{4}{ }^{2-}$ free, dried at $105{ }^{\circ} \mathrm{C}$ for a few hours, in order to obtain dehydrated samples and a constant weight, then stored in a securely closed flask against the moisture. FTIR and DXR analysis techniques were employed to characterize the powder.

\section{Characterization of the adsorbent}

Chemical analysis showed the clay used is composed essentially of silica and alumina approximately $71.5 \%$ and of iron oxide $7.30 \%$ (Table 1), the presence of ions $\mathrm{Na}^{+}, \mathrm{Ca}^{+}$and $\mathrm{K}^{+}$ in the clay gives it a swelling type. The ratio $\mathrm{SiO}_{2} / \mathrm{Al}_{2} \mathrm{O}_{3}=3.51$ reveals its montmorillonite characteristics it have both Bronsted and Lewis acid sites and when exchanged with cations having a high charge density, in the other hand (Table 1) samaruzed diference between Algerian clay and other MMT such as American and French. Raw clay from Tiout has 5.68\% more $\mathrm{SiO}_{2}$ than (Vienne, France) and $1.68 \%$ less $\mathrm{SiO}_{2}$ than (Wyoming, USA), in the other hand the raw clay from Tiout contains $5.42 \%$ and $5.32 \%$ less $\mathrm{Al}_{2} \mathrm{O}_{3}$ than the Wyoming and Vienne bentonites, respectively.

Qualitative analysis of Algerian clay is performed by FTIR transmission spectra using the $\mathrm{KBr}$ pressed disc technique. The analysis was carried out on Perkin Elmer Spectrum One FT-IR Spectrometer in the wave number range of $400-4000 \mathrm{~cm}^{-1}$. Figure 2 shows the characteristic FTIR spectra of raw clay and activated clay, their absorption band are given in (Table 2). One notices the disappearance of the band that comes out around $2071 \mathrm{~cm}^{-1}$ will be explained by the decrease in $\mathrm{Fe}_{2} \mathrm{O}_{3}$ who owed to $\mathrm{Fe}^{3+}$ exchange by the $\mathrm{H}^{+}$protons from the sulfuric acid. 
Table 1. Comparison of the composition (in \%) of American, French, and Algerian clay.

\begin{tabular}{|c|c|c|c|}
\hline Elements & $\begin{array}{c}\text { Wyoming } \\
\text { USA }\end{array}$ & $\begin{array}{c}\text { Vienne } \\
\text { French }\end{array}$ & $\begin{array}{c}\text { Tiout } \\
\text { Algeria }\end{array}$ \\
\hline $\mathrm{SiO}_{2}$ & 57.4 & 50.0 & 55.7 \\
\hline $\mathrm{Al}_{2} \mathrm{O}_{3}$ & 20.3 & 20.2 & 15.9 \\
\hline $\mathrm{Fe}_{2} \mathrm{O}_{3}$ & 2.92 & 0.68 & 7.30 \\
\hline $\mathrm{FeO}$ & 0.19 & 9 & - \\
\hline $\mathrm{CaO}$ & 0.23 & 1.46 & 2.11 \\
\hline $\mathrm{MgO}_{\mathrm{K}} \mathrm{O}$ & 3.13 & 0.23 & 4.08 \\
\hline $\mathrm{Na}_{2} \mathrm{O}$ & 0.28 & 1.27 & 1.30 \\
\hline $\mathrm{TiO}_{2}$ & 1.32 & traces & - \\
\hline $\mathrm{SO}_{3}$ & 0.12 & 0.16 & 0.43 \\
\hline $\mathrm{SO}_{3 \mathrm{gyp}}$ & - & - & 1.11 \\
\hline $\mathrm{H}_{2} \mathrm{O}$ & - & - & - \\
\hline $\mathrm{Cl}^{-}$ & 6.85 & - & 7.06 \\
\hline $\mathrm{PF}$ & - & - & \\
\hline
\end{tabular}

Table 2. FTIR spectra data of raw and activated Algerian clay.

\begin{tabular}{|l|c|}
\hline Assignement & Raw TN clay cm ${ }^{-1}$ \\
\hline Al-OH & 3620 \\
\hline H-OH stretching (for $\mathrm{H}_{2} \mathrm{O}$ ) & 3435 \\
\hline Si-O-Si stretching & 1031 \\
\hline $\mathrm{H}-\mathrm{OH}$ bending & 1638 \\
\hline $\mathrm{Si}-\mathrm{O}$ stretching ( for silice) & 797 \\
\hline $\mathrm{Si}-\mathrm{O}-\mathrm{Al}$ & 531 \\
\hline $\mathrm{Si}-\mathrm{O}-\mathrm{Mg}$ & 467 \\
\hline $\mathrm{Fe}_{2} \mathrm{O}_{3}$ & 2071 \\
\hline
\end{tabular}

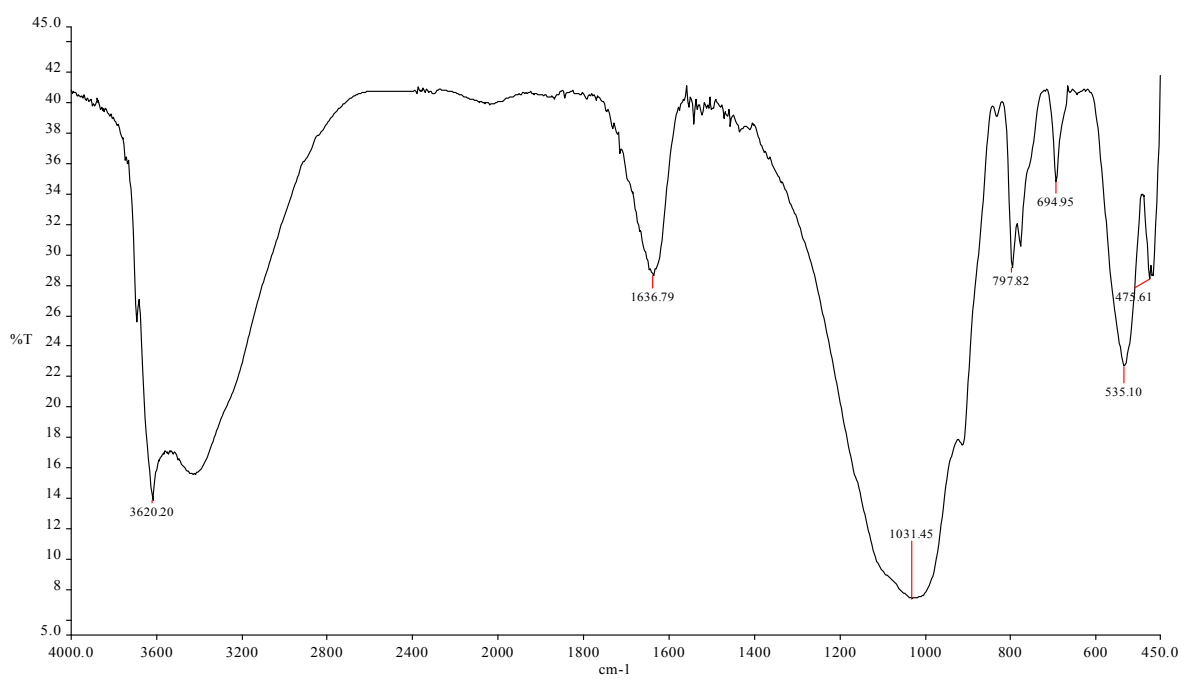

Figure 2a. FTIR spectra of activated Algerian clay.

Bull. Chem. Soc. Ethiop. 2017, 31(1) 


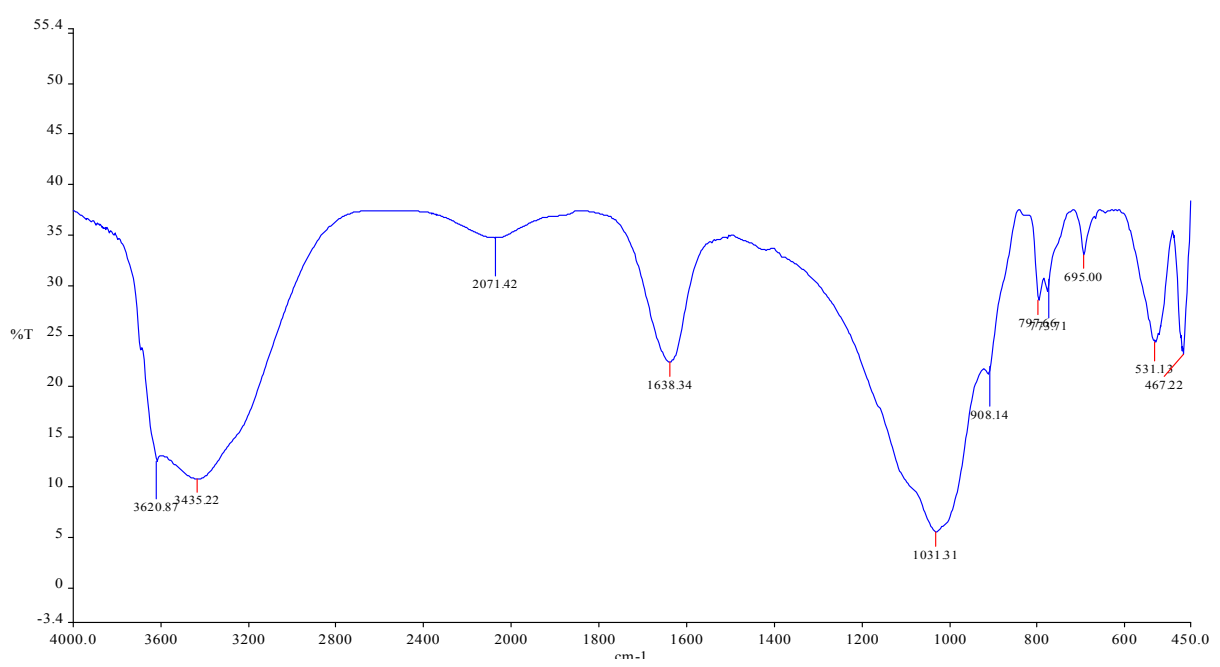

Figure 2b. FTIR spectra of natural Algerian clay.

The mineralogical composition of the natural clay and activated clay are determined by Xray diffraction (XRD) using DRX.D8 Advance Bruker generator with copper anticathode $\left(\lambda_{\mathrm{CuK} \alpha}\right.$ $=1.5406 \AA$ ). The X-ray spectrum shown in (Figure 3 ) that the raw clay is a mixture of monmorillonite and impuretes of calcite and quartz under acid traitement all traces of calcite was removed in activated clay.

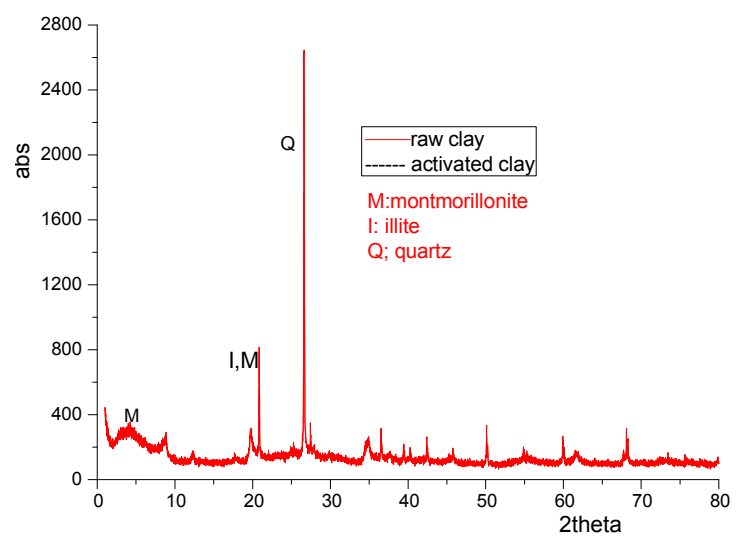

Figure 3. XDR result for raw and activated Algerian clay.

Adsorption experiments

Adsorption experiments were carried out at room temperature $\left(22 \pm 2{ }^{\circ} \mathrm{C}\right)$. Approximately $80 \mathrm{mg}$ of activated clay was weighted into flask $100 \mathrm{~mL}$ of capacity and brought into contact with 50 $\mathrm{mL}$ of dye solution with predetermined initial dye concentrations $\mathrm{C}_{0}$. The adsorption tests are perfumed at natural $\mathrm{pH}$ and under constant magnetic stirring at $450 \mathrm{rpm}$ during $30 \mathrm{~min}$ necessary time to reach adsorption equilibrium. The aqueous phase was separated by 
centrifugation at $2500 \mathrm{rpm}$ during $15 \mathrm{~min}$. The quantity of MO adsorbed is determined with UVvisible spectrophotometer (Model Shimadzu 1240) at a wavelength of $464 \mathrm{~nm}$. The equilibrium adsorption capacity $\mathrm{q}_{\mathrm{e}}(\mathrm{mg} / \mathrm{g})$ was calculated from the following equation:

$q_{e}=\left(c_{0}-c_{e}\right) \cdot \frac{v}{m}$

$\mathrm{q}_{\mathrm{e}}$ is the amount of dye adsorbed at equilibrium $(\mathrm{mg} / \mathrm{g}), \mathrm{C}_{0}$ and $\mathrm{C}_{\mathrm{e}}$ are the initial and equilibrium concentrations of the dye, respectively, computed from the calibration curve $(\mathrm{mg} / \mathrm{L})$. $\mathrm{V}$ is the volume of the solution $(\mathrm{L})$ and $\mathrm{m}$ is the mass of the adsorbent $(\mathrm{g})$.

\section{RESULTS AND DISCUSSION}

\section{Effect of contact time}

The influence of contact time is achieved at natural $\mathrm{pH}$ of the solution for an initial concentration of $26.2 \mathrm{mg} / \mathrm{L}$, with $80 \mathrm{mg} / \mathrm{L}$ of adsorbent at room temperature. The amount of dye adsorbed at time $t$ was determined by the following expression:

$q_{t}=\left(c_{0}-c_{t}\right) \cdot \frac{v}{m}$

Where $\mathrm{q}_{\mathrm{t}}$ is the amount of dye adsorbed at time $\mathrm{t}(\mathrm{mg} / \mathrm{L}), \mathrm{C}_{0}$ and $\mathrm{C}_{\mathrm{t}}$ are the concentrations of the dye at initial $(t=0)$ and at time $t$, respectively. The results are shown in Figure 4 . It can be noticed that the sorption is very fast and equilibrium between the aqueous solution and activated clay is established in less than $30 \mathrm{~min}$. the mechanism of adsorbent removal can be described in migration of the dye molecule from the solution to the adsorbent particle and diffusion through the surface [13-14]. The time of $30 \mathrm{~min}$ can be considered the saturation time.

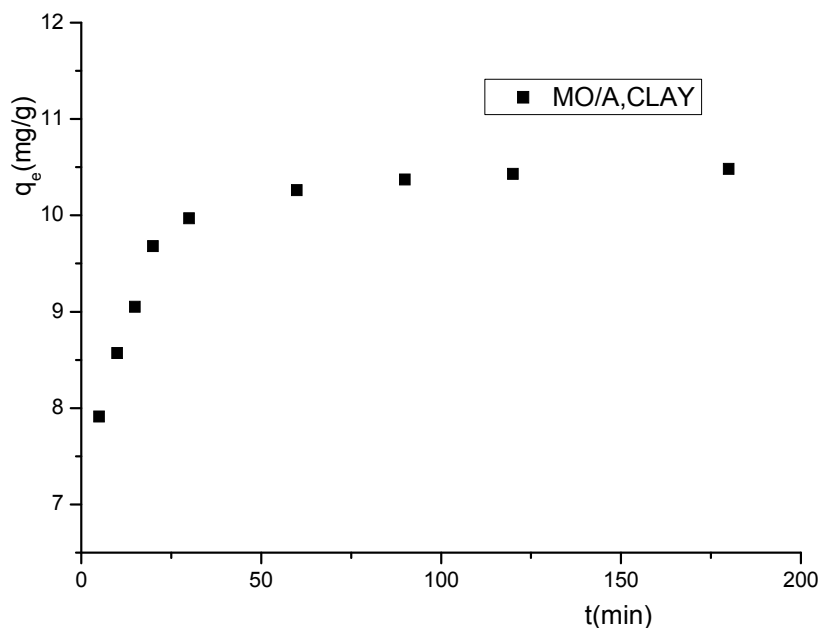

Figure 4.The effect of contact time on the adsorption of MO onto activated clay. 


\section{Kinetics order}

Many kinetic models have been applied to study the controlling mechanism of dye adsorption from aqueous solution. In order to investigate the adsorption processed of methyl orange on the adsorbent. The Pseudo-first-order model and the pseudo-second-order model were applied to fit the experimental data. The linear form of the pseudo-first-order model can be expressed by the following equation.

$$
\ln \left(q_{e}-q_{t}\right)=\ln q_{e}-k t
$$

For the pseudo-second-order model is given by the following equation.

$$
\frac{d q_{t}}{d t}=k^{\prime} \cdot\left(q_{e}-q_{t}\right)^{2}
$$

Integrating the equation (4) for the boundary conditions $\mathrm{t}=0$ to $\mathrm{t}=\mathrm{t}$ and $\mathrm{q}=0$ to $\mathrm{q}=\mathrm{q}_{\mathrm{t}}$, gives:

$$
\frac{t}{q_{t}}=\frac{1}{\left(k^{\prime} \cdot q_{e}^{2}\right)}+\frac{t}{q_{e}}
$$

Where $\mathrm{q}_{\mathrm{t}}$ is the amount of dye adsorbed $(\mathrm{mg} / \mathrm{g})$ at various time $\mathrm{t}, \mathrm{k}\left(\mathrm{min}^{-1}\right)$ and $\mathrm{k}^{\prime}(\mathrm{g} / \mathrm{mg} \cdot \mathrm{min})$ are the adsorption rate constant, qe is the maximum adsorption capacity $(\mathrm{mg} / \mathrm{g})$. The plot of $\ln \left(q_{e}-q_{t}\right)$ versus $\mathrm{t}$ for the pseudo-first-order (not mentioned in this paper) is not linear for the adsorbent, this indicate that it is not appropriate to use the pseudo-first-order model to predict the adsorption kinetic of methyl orange dye onto activated clay.

The kinetic data obtained using the pseudo-second order indicates that the $\mathrm{q}_{\mathrm{e}}$ value calculated from the pseudo-second-order model is in accordance with the experimental $\mathrm{q}_{\mathrm{e}}$ value. The correlation coefficient $\mathrm{R}^{2}$ of the linear plot is very high. The result is shown in Table 3 . Several studies found that the kinetics of adsorption of dyes on clay supports obey to the pseudo-second-order [15-18].

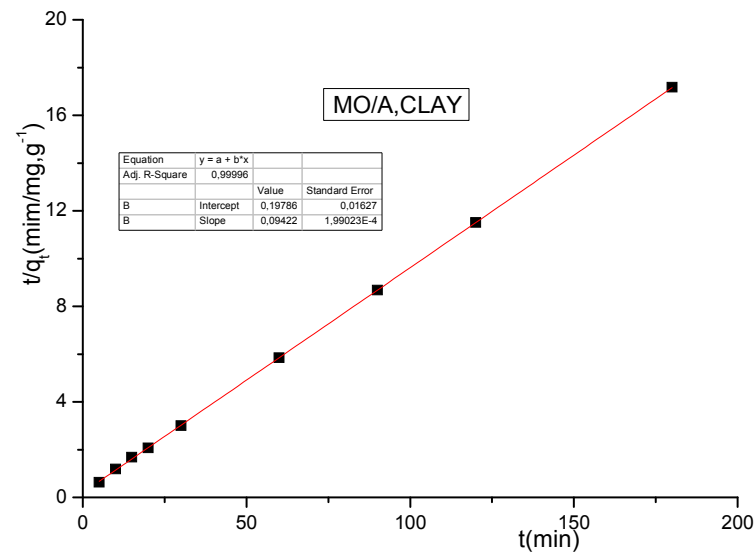

Figure 5. Pseudo-second order kinetic plot for the adsorption of MO onto activated clay. 
Table 3. The pseudo-second-order parameters of MO adsorption into activated clay.

\begin{tabular}{|l|l|}
\hline Parameters & Pseudo-second-order \\
\hline$k^{\prime}(\mathrm{g} / \mathrm{mg} \mathrm{min})$ & 0.04 \\
\hline$q_{\text {e cal }}(\mathrm{mg} / \mathrm{g})$ & 10.5 \\
\hline$q_{\text {eexp }}(\mathrm{mg} . \mathrm{g})$ & 10.6 \\
\hline$R^{2}$ & 0.99 \\
\hline
\end{tabular}

\section{Effect of adsorbent mass}

The adsorption of $\mathrm{MO}$ on adsorbent was carried by preparing $50 \mathrm{~mL}$ dye solution for $(26.2$ $\mathrm{mg} / \mathrm{L}$ ) of dye concentration and varying the adsorbent dose (1 to $4 \mathrm{~g} / \mathrm{L})$ at room temperature for $30 \mathrm{~min}$ and at natural $\mathrm{pH}$. The increase mass of adsorbent $1 \mathrm{~g} / \mathrm{L}$ down to a value of $4 \mathrm{~g} / \mathrm{L}$ causes a decreases in residual dye concentration. The increase in methyl orange adsorption with the increase in adsorbent mass is attributed to increase in surface area of micro pores and the increase in availability of vacant adsorption sites. Similar results have been reported by other authors [19-20].

\section{Effect of $p H$}

The $\mathrm{pH}$ is one of the most important factors controlling the adsorption of dye onto adsorbent. The influence of $\mathrm{pH}$ on dye removal was determined by performing the adsorption experiments at different initial $\mathrm{pH}$ of the solution (2-11) at room temperature. The $\mathrm{pH}$ had been adjusted to the desired value with $\mathrm{HCl}(0.1 \mathrm{M})$ and $\mathrm{NaOH}(0.1 \mathrm{M})$ solutions by using a HANNA $210 \mathrm{pH}-$ meter equipped with a combined $\mathrm{pH}$ electrode. The adsorption of methyl orange onto activated Algerian clay is highly dependent on $\mathrm{pH}$ of the solution.

The Figure 6 shows, at lower $\mathrm{pH}$ more protons will be available causing an increase in electrostatic attractions between negatively charged dye anions and positively charged adsorption sites and causing an increase in dye adsorption. As the $\mathrm{pH}$ of the solution increases, the positive charge on the surface decreases and the number of negatively charged sites increases. A negative charged surface site on the clay does not favour the adsorption of anionic dye due to electrostatic repulsion. Also, in alkaline medium, there will be competition, between the $\mathrm{OH}^{-}$ions and the dye anions. Similar results have been reported for the adsorption of methyl orange on clay [21-22].

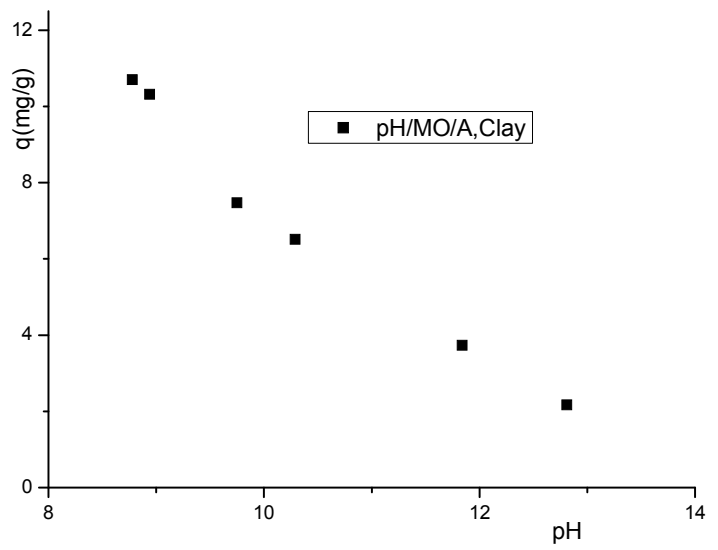

Figure 6. The effect of $\mathrm{pH}$ of the solution on the adsorption of $\mathrm{MO}$ onto activated clay.

Bull. Chem. Soc. Ethiop. 2017, 31(1) 
Effect of temperature

To observe the effect of temperature on the dye adsorption of MO by the activated clay, experiments are carried at different temperatures $\left(20,30,40,50\right.$ and $\left.60{ }^{\circ} \mathrm{C}\right)$ with $80 \mathrm{mg}$ of adsorbent was added to $50 \mathrm{~mL}$ dye solution with constant initial dye concentration of 26.2 $\mathrm{mg} / \mathrm{L}$. The contents in the flasks were agitated for $30 \mathrm{~min}$.

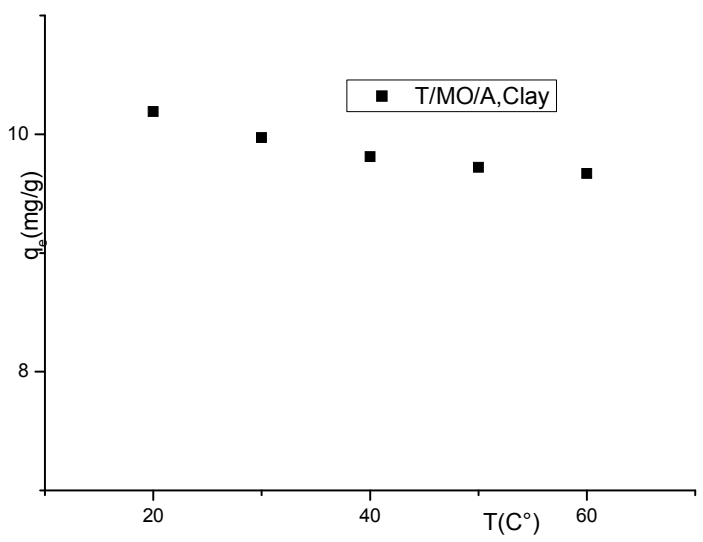

Figure 7. The effect of the temperature on the adsorption of MO onto activated clay.

The decrease in the adsorption capacity of methyl orange with increasing temperature results from the weakening of adsorptive forces between the active sites on the molecule dye and the adsorbed phase (Figure 7). Similar observations have been reported in the literature [23-24].

\section{Thermodynamic parameters}

The thermodynamics parameters studies free energy change $(\Delta G)$, enthalpy change $(\Delta H)$ and entropy change $(\Delta \mathrm{S})$ are the main thermodynamic characteristics of any adsorption system in equilibrium. The Gibbs energy $\Delta G$ is calculated from the given equation:

$\Delta G=-R T \ln k_{c}$

$k_{c}$ represented the ability of the retain of the adsorbate and extent of movement of it within the solution. The value of $k_{c}$ can be deduced from the following formula:

$k_{c}=\frac{q_{e}}{c_{e}}$

Where $\mathrm{q}_{\mathrm{e}}$ is the amount of dye adsorbed at equilibrium $(\mathrm{mg} / \mathrm{g}) . \mathrm{C}_{\mathrm{e}}$ is the equilibrium concentration of the dye in the solution. The thermodynamic equation:

$\Delta G=\Delta H-T \Delta S$

And the Van't Hoff equation:

$\Delta G=-R T \ln k_{c}$

Can be deduced the following formula: 
$\operatorname{lnk}_{c}=\frac{\Delta S}{R}-\frac{\Delta H}{R} \cdot \frac{1}{T}$

The values of $\Delta S$ and $\Delta H$ can be obtained by plot of ln kc versus (1/T) are shown in Figure 10.

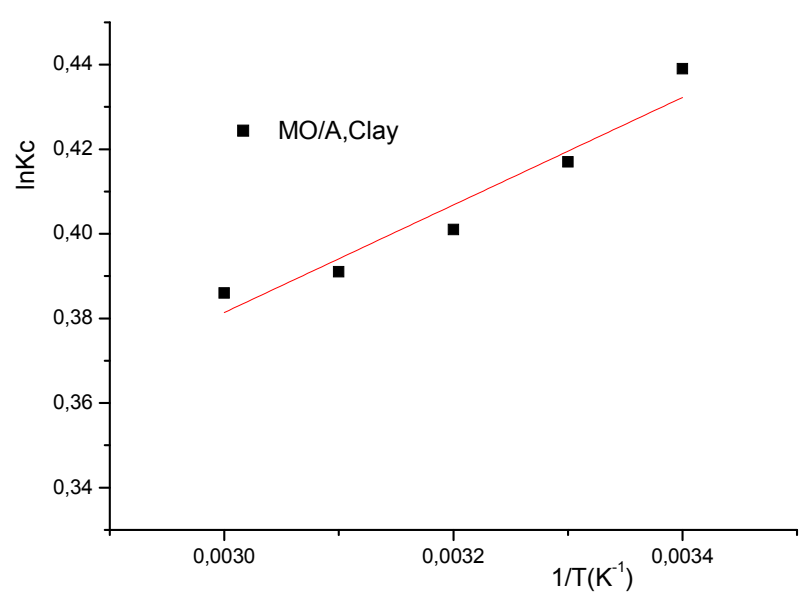

Figure 8. Plot of $\ln K c$ versus $1 / T$ for the estimation of thermodynamic parameters.

Thermodynamic parameters for the adsorption of methyl orange on activated Algerian clay are given in Table 4 . The negative values of $\Delta \mathrm{G}$ for adsorbent at various temperatures indicate the process to be feasible and spontaneous. The positive value of $\Delta \mathrm{H}$ confirms the endothermic nature of the adsorption process and indicates that the type of adsorption is chemical nature. The positive value of $\Delta \mathrm{S}$ suggests randomness at the solid/liquid interface in the adsorption system increases during the adsorption process [25].

Table 4. Thermodynamic parameters of MO adsorption into activated clay.

\begin{tabular}{|c|c|c|c|c|c|c|}
\hline Adsorbent & Colorant & $\mathrm{T}(\mathrm{K})$ & $\Delta \mathrm{G}(\mathrm{kJ} / \mathrm{mol})$ & $\Delta \mathrm{H}(\mathrm{J} / \mathrm{mol})$ & $\Delta \mathrm{S}(\mathrm{J} / \mathrm{mol} . \mathrm{K})$ & $\mathrm{R}^{2}$ \\
\hline \multirow{3}{*}{$\begin{array}{c}\text { Activated } \\
\text { Algerian } \\
\text { clay }\end{array}$} & \multirow{3}{*}{$\mathrm{MO}$} & 293 & -1.06 & 1030.52 & 3.35 & \multirow{2}{*}{0.98} \\
\cline { 3 - 6 } & & 303 & -1.05 & - & - & \\
\cline { 3 - 6 } & & 313 & -1.04 & - & - \\
\cline { 3 - 6 } & & 323 & -1.05 & - & - & \\
\cline { 3 - 6 } & 333 & -1.06 & - & - & \\
\hline
\end{tabular}

Adsorption isotherms and models

An adsorption isotherm is the presentation of the amount of solute adsorbed per unit weight of adsorbent as a function of the equilibrium concentration in the bulk solution at constant temperature. Langmuir and Freundlich adsorption isotherms are commonly used for the description of adsorption data.

The Langmuir isotherm is valid for monolayer adsorption onto a surface with a finite number of identical sites. The homogeneous Langmuir adsorption isotherm is represented by the following equation.

$q_{e}=q_{\max } \times b \cdot C_{e} /\left(1+b \cdot C_{e}\right)$ 
Where $q_{e}$ is the amount adsorbed at equilibrium $(\mathrm{mg} / \mathrm{g}), C_{e}$ is the equilibrium concentration $(\mathrm{mg} / \mathrm{L}), b$ is a constant related to the adsorption energy $(\mathrm{L} / \mathrm{mg})$, and $q_{\max }$ is the maximum adsorption capacity $(\mathrm{mg} / \mathrm{g})$.

The linear form of Langmuir equation may be written as:

$\frac{1}{q_{e}}=\frac{1}{q_{\max }}+\frac{1}{b} \cdot \frac{1}{c_{e}}$

By plotting $\left(1 / q_{e}\right)$ versus $C_{e}, q_{\max } a n d b$ can be determined if a straight line is obtained.

The Freundlich isotherm is an empirical equation assuming that the adsorption process takes place on heterogeneous surfaces, and adsorption capacity is related to the concentration of colorant at equilibrium. The heterogeneous Freundlich adsorption isotherm is represented by the following equation:

$q_{e}=c_{e}^{1 / n} \cdot K_{F}$

Where the $K_{F}$ is Freundlich constant related to the adsorption capacity $(\mathrm{mg} / \mathrm{g})$ and $1 / \mathrm{n}$ is indicative of the energy or intensity of the reaction and suggests the favourability and capacity of the adsorbent/adsorbate systems (L/mg).

The linear form of Freundlich equation may be written as

$$
\log q_{e}=\frac{1}{n} \cdot \log \mathrm{c}_{e}+\log K_{F}
$$

The values of $K_{F}$ and $\frac{1}{n}$ can be determined by plotting the $\log q_{e}$ versus $\log C_{e}$, if a straight line is obtained.

The isotherm parameters for the adsorption of MO onto activated clay are summarised in Table 5. It can be seen, the result revealed that the adsorption of methyl orange dye onto activated clay was the best-fit both Langmuir and Freundlich isotherms. Furthermore, values of $1 / \mathrm{n}$ were between zero and one, which indicates that activated clay is favourable for the adsorption of MO dye under the experimental conditions employed [25]. The comparison of adsorption capacities of various materials is given in Table 6 .

Table 5. Isotherm constants for adsorption of methyl orange into activated clay.

\begin{tabular}{|l|c|c|}
\hline Paramaters & Langmuir & Freundlich \\
\hline $\mathrm{Q}_{\max }(\mathrm{mg} / \mathrm{g})$ & 32.6 & - \\
\hline $\mathrm{b}$ & 1.25 & - \\
\hline $\mathrm{R}^{2}$ & 0.99 & 0.96 \\
\hline $\log \mathrm{K}_{\mathrm{F}}$ & - & 0.07 \\
\hline $1 / \mathrm{n}$ & - & 0.87 \\
\hline
\end{tabular}

Table 6. Comparison of the adsorption capacity of dyes onto adsorbents such as clay.

\begin{tabular}{|l|c|c|c|}
\hline Adsorbent & Adsorbate & Adsorption capacity (mg/g) & Reference \\
\hline Bentonite & Malachite green & 7.72 & {$[26]$} \\
\hline Bentonite algeria & Rouge bezanyl & 39.1 & {$[15]$} \\
\hline $\begin{array}{l}\text { Na-Bentonite and Ca-Bento- } \\
\text { nitecrude and purified clay }\end{array}$ & Basic violet 14 & 148 and 100 & {$[27]$} \\
\hline $\begin{array}{l}\text { Chitosan intercalated } \\
\text { montmorillonite }\end{array}$ & Methylene blue & 50.0 and 68.5 & {$[28]$} \\
\hline Natural clay & Methyl orange & 70.4 & {$[29]$} \\
\hline Cu(II)-loaded MMT & Crystal violet & 25.0 and 42.0 & {$[29]$} \\
\hline Activated Algerian clay & Methyl orange & 32.3 & In this study \\
\hline
\end{tabular}

Bull. Chem. Soc. Ethiop. 2017, 31(1) 


\section{CONCLUSION}

The adsorption parameters of methyl orange onto the activated clay from aqueous solution have been evaluated in this study. The results showed that nearly $30 \mathrm{~min}$ of contact time are found to be sufficient for the adsorption to reach equilibrium and when the amount of activated clay increases from $1 \mathrm{~g} / \mathrm{L}$ to a value of $4 \mathrm{~g} / \mathrm{L}$ causes decreases in residual dye concentration. The value of kinetic constant and $\mathrm{q}_{\mathrm{e}}$ indicates that the adsorption follow the pseudo-second order model. The adsorption capacity of methyl orange onto activated clay decreases with increasing $\mathrm{pH}$ of the medium. The negative value of $\Delta \mathrm{G}$ indicates that the adsorption is done through a spontaneous and favourable process; the positive value of $\Delta \mathrm{H}$ confirms the endothermic nature of the adsorption process and indicates that the type of adsorption is chemical nature. The positive value of $\Delta \mathrm{S}$ suggests randomness at the solid/liquid interface in the adsorption system increases during the adsorption process. The result revealed that the adsorption of methyl orange dye onto activated clay was the best-fit both Langmuir and Freundlich isotherms and the maximum adsorption capacity given by the Langmuir model was $32.3 \mathrm{mg} / \mathrm{g}$ at natural $\mathrm{pH}$ and at room temperature.

\section{REFERENCES}

1. Annodurai, G.; Ling, L.Y.; Lee, J.F. Adsorption of reactive dye from an aqueous solution by chitosan: Isotherm, kinetic and thermodynamic analysis. J. Hazard. Mater. 2008, 152, $337-$ 346.

2. Salleh, M.A.M.; Mahmoud, D.K.; Karin, W.A.; Idris, A. Cationic and anionic dye adsorption by agricultural solid wastes: A comprehensive review. Desalination 2011, 280, $1-13$.

3. Shi, B.Y.; Li, G.H.; Wang, D.S.; Feng, C.H.; Tang, H.X. Removal of direct dyes by coagulation the performance of preformed polymeric aluminum species. J. Hazard. Mater. 2007, 143, 567-574.

4. Nkurunziza, T.; Nduwayezu, J.B.; Banadda E.N.; Nhapi, I. The effect of turbidity levels and Moringa oleifera concentration on the effectiveness of coagulation in water treatment. $J$. Water Sci. Technol. 2009, 59, 1551-1558.

5. Khenifi, A.; Sekrane, F.; Kameche, M. Adsorption study of an industrial dye by an organic clay. J. Adsorption 2007, 13, 149-158.

6. Chen, S.; Zhang, J. ; Zhang, C.; Yue, Q.; Li, Y.; Li, C. Equilibrium and kinetic studies of methyl orange and methyl violet adsorption on activated carbon derived from Phragmites australis. Desalination 2010, 252, 149-156.

7. Robinson, T.; Chandran, B.; Nigam, P. Removal of dyes from an artificial textile dye effluent by two agricultural waste residues, corncob and barley husk. J. Environ. Int. 2002, 28, 298-333.

8. Ferrahi, M.I.; Belbachir, M. Synthesis of cyclic polyesters of poly(oxybutylene oxymaleoyl). J. Polym. Res. 2005, 12, 167-170.

9. Ismail, M.A.; Eltayeb, M.A.Z.; Abdel Maged, S.A. Elimination of heavy metals from aqueous solutions using zeolite LTA synthesized from Sudanese clay. Res. J. Chem. Sci. 2013, 3, 93-98.

10. Mdoe, J.E.G.; Makene, J.S.M. Removal of lead(II) ions from aqueous solutions using cashew nut shell liquid-templated thiol-silica materials. Bull. Chem. Soc. Ethiop. 2014, 28, 363-372.

11. Mohammadi, S.Z.; Shamspur, T.; Baghelani, Y.M. Combination of flame atomic absorption spectrometry with ligandless-dispersive liquid-liquid microextraction for preconcentration and determination of trace amount of lead in water samples. Bull. Chem. Soc. Ethiop. 2013, 27,161 . 
12. Wibulswas, R. Bach and fixed bed sorption of methylene blue on precursor and QUACs modified montmorillonite. Sep. Purif. Technol. 2004, 39, 3-12.

13. Amari, A.; Chlendi, M.; Gannouni, A.; Bellagi, A. Optimization by response surface methodology (RSM) for toluene adsorption onto prepared acid activated clay Appl. Clay Sci. 2010, 47, 457-461.

14. Franco, F. Adsorption of methylene blue on magnesium silicate, kinetics, equilibrium and comparison with other adsorbents. J. Environ. Sci. 2010, 22, 467-473.

15. Benguella, B.; Yacouta-Nour, élimination des colorants acides en solution aqueuse par la bentonite et le kaolin. J. C. R. Chimie 2009, 12, 762-771.

16. Bhakta, J.N; Munekage, Y. Identification of potential soil adsorbent for the removal of hazardous metals from aqueous phase. Int. J. Environ. Sci. Technol. 2013, 10, 316-324.

17. Fil, B.A.; Yilmaz, M.T.; Bayar, S.; Elkoca, M.T. Investigation of adsorption of the dyestuff astrazon red violet 3rn (basic violet 16) on montmorillonite clay. Braz. J. Chem. Eng. 2014, 33, 172-182.

18. Ozcan, A.S.; Ozcan, A. Adsorption of acid dyes from aqueous solutions onto acid-activated bentonite. J. Colloid Interface. Sci. 2004, 276, 39-46.

19. Teng, M.Y.; Lin, S.H. Removal of methyl orange dye from water onto raw and acid activated montmorillonite in fixed beds. Desalination 2006, 201, 71-81.

20. Rafatullah, M.; Sulaiman, O.; Hashim, R.; Ahmad, A. Adsorption of methylene blue on lowcost adsorbents: a review. J. Hazard. Mater. 2010, 177, 70-80.

21. Venkat, S.M.; Indra, D.M.; Vimal, C.S.J. Use of bagasse fly ash as an adsorbent for the removal of brilliant green dye from aqueous solution. Dyes Pigments 2007, 73, 269-278.

22. Al-Asheh, S.; Banat, F.; Abu-Aitah, L. Adsorption of phenol using different types of activated bentonites. Sep. Purif. Technol. 2003, 33, 1-10.

23. Kara, M.; Yuzer; H.; Sabah, E.; Celik, M.S. Adsorption of cobalt from aqueous solutions onto sepiolite. Water Res. 2003, 37, 224-232

24. Babel, S.; Kurniawan, T.A. Low-cost adsorbents for heavy metals uptake from contaminated water: A review. J. Hazard. Mater. 2003, 28, 219-43.

25. Ahmet, S.; Ömer, I. Adsorption properties of stearic acid onto untreated kaolinite. Bull. Chem. Soc. Ethiop. 2006, 20, 259-267.

26. Tahir, S.S; Rauf, N. Removal of a cationic dye from aqueous solutions by adsorption onto bentonite clay. Chemosphere 2006, 63, 1842-1848.

27. Jiang, Y.-X.; Xu, H.-J; Liang, D.-W; and Tong, Z.-F. Adsorption of Basic Violet 14 from aqueous solution on bentonite. Comptes Rendus Chimie 2008, 11, 125-129.

28. Karim, A.B.; Mounir, B.; Hachkar, M.; Bakasse, M.; and Yaacoubi, A. Removal of basic dye "methylene blue" in aqueous solution by Safi clay. Revue des Sciences de l'Eau 2010, 23, 375-388.

29. Chakkrit, U.; Songsak, S. Removal of methyl orange from aqueous solutions by adsorption using chitosan intercalated montmorillonite. Songklanakarin J. Sci. Technol. 2013, 35, 451459 . 